\title{
Avaliação da sustentabilidade socioambiental no gerenciamento de resíduos sólidos no Município de São José de Piranhas, Estado da Paraíba, Nordeste do Brasil
}

\section{André Lima Leite ${ }^{1}$ e José Deomar de Souza Barros ${ }^{2}$}

${ }^{1}$ Universidade Federal de Campina Grande (UFCG). Centro de Formação de Professores. Grupo de Pesquisa Ambiental para o Desenvolvimento do Semiárido (GPA). Rua Sérgio Moreira de Figueiredo, s/nํ․ Casas Populares. Cajazeiras-PB, Brasil (58900-000).

${ }^{2}$ Universidade Federal de Campina Grande (UFCG). Centro de Formação de Professores. Grupo de Pesquisa Ambiental para o Desenvolvimento do Semiárido (GPA). Rua Sérgio Moreira de Figueiredo, s/no․ Casas Populares. Cajazeiras-PB, Brasil (58900-000). E-mail: deomarbarros@gmail.com.

Resumo. 0 aumento da população mundial nos últimos anos, aliado ao aumento do consumismo contribuiu para a elevação da produção de resíduos sólidos. Com isso inúmeros estudos vêm surgindo, buscando encontrar soluções para a problemática do gerenciamento desses resíduos. A presente pesquisa avaliou como ocorre o gerenciamento dos resíduos sólidos da zona urbana do Município de São José de Piranhas, Estado da Paraíba, Nordeste do Brasil. 0 estudo ocorreu entre os meses de junho e dezembro de 2018. Para a efetivação desta pesquisa foi realizado um levantamento bibliográfico acerca do tema abordado e a coleta dos dados foi realizada por meio de entrevistas. Participaram da pesquisa representantes de diversos segmentos sociais, como representantes do poder público, da iniciativa privada e população em geral. Para a análise dos dados coletados foi utilizado o sistema de indicadores Pressão-Estado-ImpactoResposta (PEIR). Os resultados indicam que o município apresenta uma elevada produção de lixo, e a população não tem acesso a uma educação ambiental de qualidade, haja visto que dos oito indicadores de pressão, cinco são classificados como desfavoráveis, todos os indicadores de estado são classificados como desfavoráveis, dos seis indicadores de impacto, três são vistos como desfavoráveis, e todos os indicadores de resposta são classificados como desfavoráveis a sustentabilidade. Assim a pesquisa evidenciou a necessidade de mudanças imediatas no gerenciamento dos resíduos sólidos no Município de São José de Piranhas.

Palavras-chave: Resíduos sólidos; Gerenciamento; Sustentabilidade.
Recebido $26 / 07 / 2019$

Aceito

$30 / 11 / 2019$

Disponível on line

01/12/2019

Publicado

31/12/2019

Acesso aberto

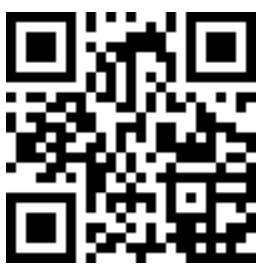

0000-0002-3200-9670 André Lima Leite

(1) 0000-0003-3785-9823 José Deomar de Souza Barros 


\begin{abstract}
Evaluation of socio-environmental sustainability in solid waste management in the Municipality of São José de Piranhas, State of Paraíba, Northeast Brazil. Increases in the world population and consumerism have contributed to an increase in the generation of solid waste. Numerous studies have sought solutions for solid waste management. The aim of the present study was to evaluate solid waste management in the urban zone of the Municipality of São José de Piranhas in the State of Paraíba, Northeast Brazil. The study was conducted between June and December 2018. A bibliographic survey was first performed on the topic and data were collected through interviews with representatives of diverse social segments (public administrators, private enterprise and the general population). The pressure-state-impact-response system of indicators was used for the data analysis. The results indicate that the municipality has high solid waste production and the population has no access to environmental education of quality, as five of the eight pressure indicators, all of the state indicators, three of the six impact indicators and all of the response indicators were classified as unfavorable with regard to sustainability. The present findings underscore the need for immediate changes in the management of solid waste in the Municipality of São José de Piranhas.
\end{abstract}

Keywords: Solid waste; Management; Sustainability.

\section{Introdução}

A população mundial sofreu nos últimos anos um súbito aumento, o que acaba contribuindo de maneira direta para a produção de resíduos sólidos devido ao consumismo exacerbado, que é corriqueiro na contemporaneidade. A quantidade de resíduos produzidos por pessoa passou de 1,062 (kg/hab./dia) em 2014, para 1,071 (kg/hab./dia) em 2015, uma elevação de $0,8 \%$ na produção de Resíduos Sólidos Urbanos (RSU), sendo este um dado preocupante para o meio ambiente (ABRELPE, 2015).

A contaminação do ambiente a partir dos poluentes gerados pelo desenvolvimento industrial vem sendo considerada, nos últimos anos, um problema extremamente complexo e merecedor de estudo. A industrialização ocorreu como forma de viabilizar o desenvolvimento da economia, porém, pouco se falou em planejamento urbano e medidas ambientais, que se antecipassem às futuras problemáticas que poderiam surgir, e assim contribuir de maneira efetiva na resolução dos problemas ambientais existentes (Oliveira, 2006).

De acordo com a Resolução CONAMA no 001/1986 (Brasil, 1986) é considerado impacto ambiental qualquer alteração das propriedades físicas, químicas e biológicas do meio ambiente, causada por qualquer forma de matéria ou energia resultante das atividades humanas que, direta ou indiretamente afetam a integridade das pessoas ou do meio ambiente no qual as ações ocorrem.

Uma das formas de se efetuar a verificação da qualidade ambiental de determinado local é através do sistema de Pressão - Estado - Impacto - Resposta (PEIR), sendo este caracterizado por tratar-se de um programa de comunicação que tem como objetivo sensibilizar à respeito das questões ambientais, oferecendo assim opções para ações, através das quais seja possível, dentre outras atribuições, fazer análise de medidas corretivas, adotar 
novos rumos no enfrentamento dos problemas ambientais, assim como identificar competências e níveis de responsabilidade dos agentes sociais comprometidos (Silva et al., 2012a).

Para solucionar os problemas apontados pelo sistema PEIR, muitas ações se fazem necessárias, tais como coleta seletiva, implantação de aterro sanitário, extinção dos chamados lixões e a reciclagem dos resíduos. Os geradores, que são todas as pessoas que produzem 0 "lixo", devem ter consciência plena de que é essencial diminuir o consumo supérfluo, evitar desperdícios e separar o material reciclável na origem (residência, indústria, comércio), reaproveitando os produtos ao máximo para que o exercício do consumo consciente seja uma alternativa viável e eficaz (Silva et al., 2012b).

Assim, a pesquisa buscou avaliar como ocorre o gerenciamento dos resíduos sólidos da zona urbana do Município de São José de Piranhas, Estado da Paraíba, Nordeste do Brasil.

\section{Procedimento metodológico}

A presente pesquisa foi realizada no Município de São José de Piranhas, no período entre junho e dezembro de 2018, obedecendo às diretrizes da Resolução CNS no 510/2016, que assegura que os participantes dela devem ser informados da destinação, uso e sigilo das informações obtidas (Brasil, 2016).

\section{estudo}

Caracterização da área de

O Município de São José de Piranhas (coordenadas geográficas de referência, $7^{\circ} 7^{\prime} 5^{\prime \prime}$ de latitude sul e $38^{\circ} 30^{\prime} 5^{\prime \prime}$ de longitude oeste) está localizado no Alto Sertão Paraibano (Figura 1), a cerca de $27 \mathrm{~km}$ a Sul-Leste do Município de Cajazeiras. No ano de 2017 sua população era estimada em 20.163 pessoas, distribuídas entre zona rural e zona urbana, sendo o presente trabalho realizado exclusivamente na zona urbana. Apresenta uma área territorial de $677 \mathrm{~km}^{2}$, e está situado a cerca de $332 \mathrm{~m}$ de altitude (IBGE, 2010).

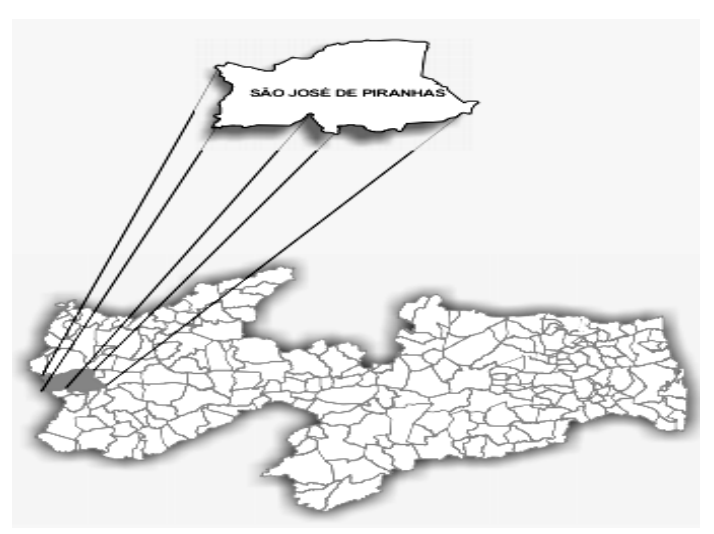

Figura 1. Localização do Município de São José de Piranhas dentro do território paraibano. Fonte: CPRM (2015).

\section{Classificação da pesquisa}

Tomando por base Silva e Meneses (2005) e Prodanov e Freitas (2013) do ponto de vista da natureza, a pesquisa é aplicada, tendo em vista que ela busca criar conhecimentos de aplicação prática voltados a solucionar problemas específicos. Com relação a forma de abordagem a pesquisa é considerada tanto quantitativa, quanto qualitativa, tendo em vista que na abordagem quantitativa se faz necessária a transformação dos números obtidos em informações a serem analisadas, já no perfil qualitativo é necessário a interpretação dos fenômenos e atribuição dos seus significados. Quanto aos seus objetivos a pesquisa é classificada como descritiva, pois expõe as características de uma determinada população ou fenômeno, a partir de técnicas padronizadas de coleta de dados. É também classificada como explicativa, pois procura identificar os fatores que causam um determinado fenômeno, aprofundando o conhecimento da realidade. Já em relação aos procedimentos técnicos, a pesquisa é classificada como um estudo de caso, haja visto que representa a estratégia 
preferida quando são colocadas indagações do tipo "como" e "por que", quando $o$ pesquisador tem pouco controle sobre os eventos e quando o foco se encontra em fenômenos contemporâneos inseridos em algum contexto da vida real.

\section{Sujeitos da pesquisa}

Com relação ao público entrevistado na pesquisa, foram consultados representantes do poder público como, vereadores e secretários municipais, servidores da limpeza urbana, catadores, representantes de associações e escolas, funcionários de unidades de saúde do município, comerciantes e moradores dos bairros que compõem o município, como está detalhado na Tabela 1, enfim, todos os atores sociais e institucionais que atuam de forma direta ou indireta com a temática trabalhada.

\section{População, amostra e amostragem}

A pesquisa contou com a participação da população do Município de São José de Piranhas-PB, sendo a amostra composta por 51 habitantes, estes denominados de atores sociais e institucionais, com relação direta ou indireta com a problemática ambiental desta pesquisa, sendo estes descritos na Tabela 1.

Tabela 1. Número de entrevistas junto aos atores sociais e institucionais.

\begin{tabular}{|l|c|}
\hline Atores sociais e institucionais & Número de entrevistados \\
\hline Representantes do poder público & 7 \\
\hline Moradores de bairros & 25 \\
\hline Representantes de associações e escolas & 4 \\
\hline Agentes de limpeza & 5 \\
\hline Catadores & 2 \\
\hline Comerciantes & 3 \\
\hline $\begin{array}{l}\text { Lideranças sociais (líderes religiosos e } \\
\text { presidentes de associações comunitárias) }\end{array}$ & 5 \\
\hline Total & 51 \\
\hline
\end{tabular}

Fonte: Adaptado de Soares et al. (2017).

\section{Instrumento de coleta de dados}

Foi utilizado questionário para obter as informações necessárias à pesquisa, e ainda foram realizada visitas ao local de disposição dos resíduos sólidos para verificar a situação na qual o mesmo se encontra. A referida pesquisa foi aprovada pelo Comitê de Ética em Pesquisa (CEP), CAAE 90662718.0.0000.5575.

\section{Análise dos dados}

Para se efetuar a análise dos dados foi feito uso de uma abordagem quali-quantitativa, com o intuito de avaliar o gerenciamento de resíduos sólidos por meio do sistema de indicadores de sustentabilidade PressãoEstado-Impacto-Resposta (PEIR) no Município de São José de Piranhas, Estado da Paraíba. Os indicadores foram avaliados utilizando-se os critérios de "favorável" ou "desfavorável" do ponto de vista da sustentabilidade.

\section{Resultados e discussão}

\section{Pressão}

Análise dos Indicadores de

Coleta de lixo diretamente para

o lixão. De acordo com o IBGE (Instituto Brasileiro de Geografia e Estatística) o 
acesso à coleta de lixo doméstico é apresentado como um forte indicador do desenvolvimento sustentável, advertindo ainda, que em casos onde os resíduos não são coletados ou dispostos em locais indevidos podem acarretar em sérios danos ambientais, bem como em danos à saúde das pessoas.

Em consonância com os 51 atores sociais entrevistados, ficou evidente que, de fato, é realizado com frequência a coleta dos resíduos, levando os mesmos até o local de disposição, que trata-se de um vazadouro a céu aberto (Figura 2), popularmente conhecido como lixão. Essa atividade ocorre diariamente, sendo que em cada bairro da cidade a coleta ocorre duas vezes por semana.

Em uma pesquisa realizada por Moreira et al. (2017), no Município de Aurora, Estado Ceará, este indicador foi classificado como desfavorável em virtude da existência de vazadouro a céu aberto. O Município de São José de Piranhas também encontra-se na mesma condição, ou seja, utilizando o vazadouro a céu aberto. Desse modo, esse indicador fica avaliado como DESFAVORÁVEL à sustentabilidade ambiental.

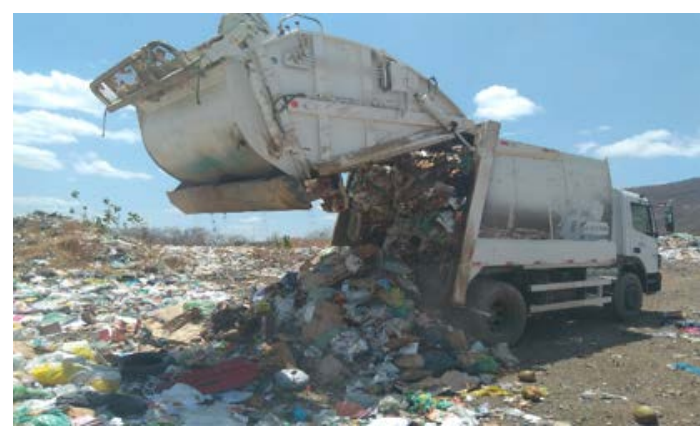

Figura 2. Despejo do lixo coletado diretamente no lixão, 2018.

Coleta de lixo nos bairros. De acordo com Cunha e Caixeta Filho (2002) o processo de coleta dos resíduos sólidos engloba desde a partida do veículo de sua garagem, compreendendo todo $\mathrm{o}$ percurso gasto na viagem para remoção dos resíduos dos locais onde foram acondicionados aos locais de descarga, até o retorno ao ponto de partida. A coleta em geral é classificada em dois tipos de sistemas: sistema especial de coleta (resíduos contaminados) e sistema de coleta de resíduos não contaminados. Nesse último, a coleta pode ser realizada de maneira convencional (resíduos são encaminhados para o destino final) ou seletiva (resíduos recicláveis que são encaminhados para locais de tratamento e/ou recuperação).

Em São José de Piranhas a coleta dos resíduos ocorre diariamente (Figura $3)$, porém não é feita de maneira seletiva, contudo, essa ação permite que o lixo seja colocado em um local mais distante da população. Desta forma este indicador é avaliado como FAVORÁVEL à sustentabilidade municipal devido a coleta de lixo acontecer em todos os bairros.

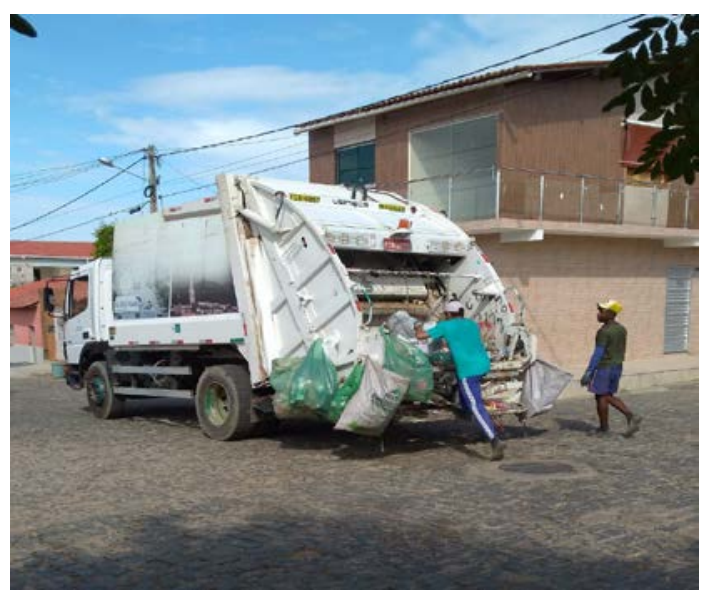

Figura 3. Coleta de lixo nos bairros da Cidade de São José de Piranhas, 2018.

\section{Queima de resíduos a céu} aberto. A incineração pode ser ambientalmente correta e aliada a proteção do meio ambiente, desde que existam especialistas dotados de equipamento eficazes quanto ao controle da poluição, bem como, de técnicas adequadas de disposição final dos 
resíduos gerados, e haja o monitoramento e acompanhamento pela comunidade e por agentes ambientais, públicos e privados (Morgado e Ferreira, 2006).

Em consonância com o exposto no trabalho realizado no Município de Nazarezinho, Estado da Paraíba, por Soares et al. (2017), verificou-se que em São José de Piranhas, os resíduos sólidos provenientes do descarte da população são destinados a um vazadouro a céu aberto. E de acordo com todos os atores sociais consultados, ocorre com frequência a queima dos resíduos (Figura 4). A fumaça liberada com a incineração é o principal motivo de queixa da população, principalmente por parte daqueles que moram nos bairros mais próximos ao vazadouro.

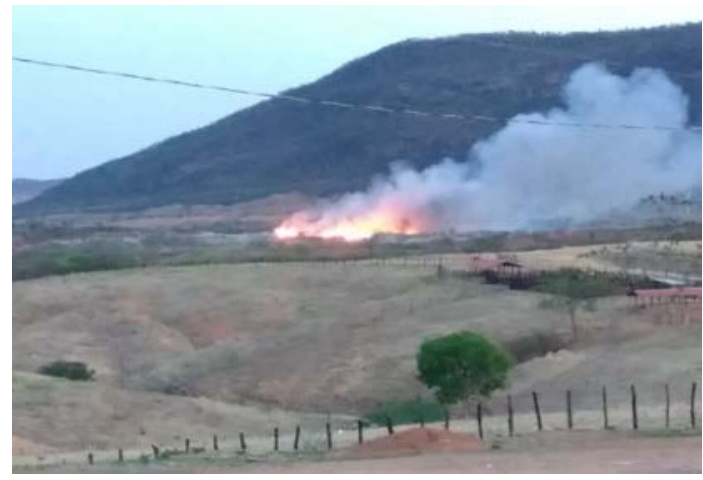

Figura 4. Queima de resíduos a céu aberto ocorrendo no vazadouro de São José de Piranhas, 2018.

Mesmo esta prática sendo bastante antiga os atores institucionais mais envolvidos alegaram não ter conhecimento de quem são os responsáveis pela incineração. Assim, este indicador é classificado como DESFAVORÁVEL à sustentabilidade do município pela ocorrência de incêndios na área de disposição dos resíduos e pela liberação de gases poluidores.

Presença de animais na área de disposição do lixo. A área de disposição dos resíduos localiza-se muito próximo a zona urbana do município, e o vazadouro, mesmo possuindo cercas, possui locais que permitem a passagem de animais e pessoas, assim é possível observar a presença dos animais no local, sendo facilmente constatado a presença de cães (Figura 5), além da ocorrência também de urubus (Figura 6) e, principalmente, de grandes vetores de doenças como os ratos e moscas.

Assim, o vazadouro está aberto para o acesso de qualquer tipo de animal, o que acarreta em um contato direto com o lixo depositado no local, o que avalia este indicador como DESFAVORÁVEL à sustentabilidade.

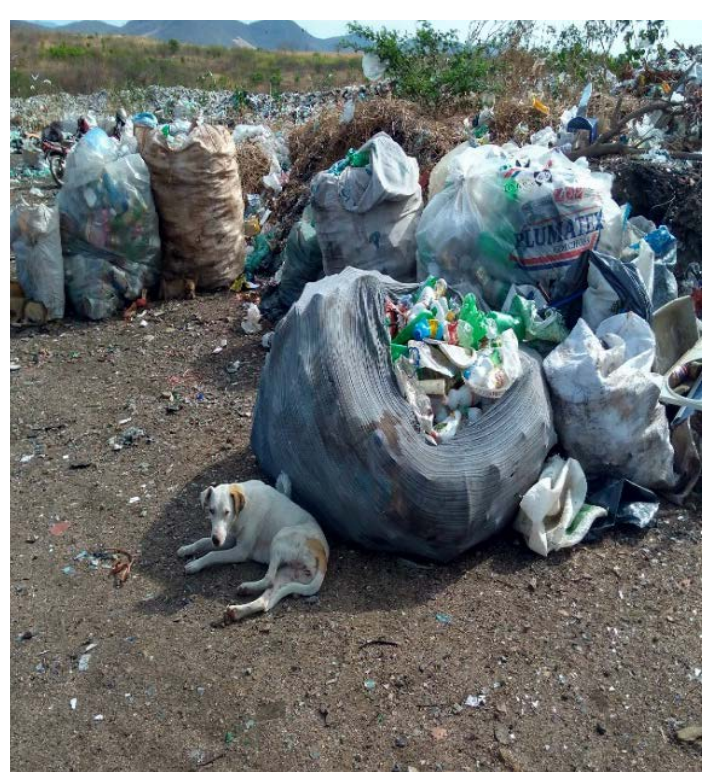

Figura 5. Presença de cães no lixão do Município de São José de Piranhas, 2018.

Moradias na unidade de disposição. É comum pessoas que não possuem moradia, e principalmente os catadores autônomos, residirem nas áreas de disposição do lixo, já que é de lá que eles tiram todo o seu sustento. Esse tipo de residência que apresenta sérios riscos à saúde dessas pessoas é "justificada" pelo baixo custo que há em 
se morar dentro de um vazadouro de resíduos sólidos.

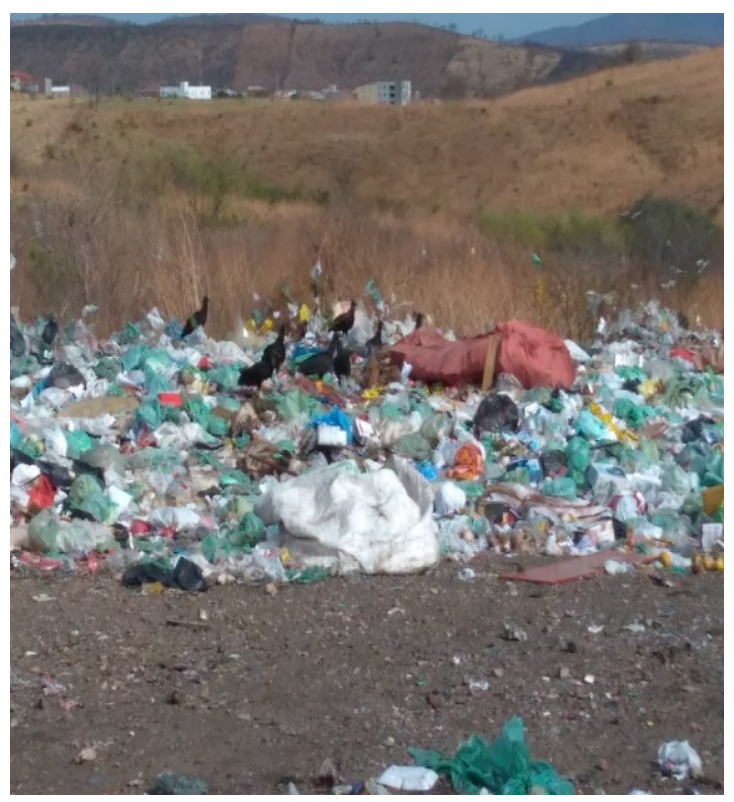

Figura 6. Presença de Urubus no lixão do Município de São José de Piranhas, 2018.

Em São José de Piranhas não existe nenhuma moradia na localidade de disposição, no entanto, alguns dos atores sociais entrevistados afirmaram que haviam sim residências no vazadouro, e que eles mesmos já haviam visto elas há alguns anos, contudo, atualmente não há nenhuma família ou pessoa morando dentro do lixão. Desse modo, por não haver nenhuma residência no vazadouro o indicador pode ser avaliado como FAVORÁVEL.

Existência de catadores. Os catadores constituem-se em uma comunidade de risco e poucos são os estudos que relacionam os riscos à saúde pública na atividade de catação. Em uma abordagem mais pontual do tema, especificamente com o foco no trabalhador, muitos trabalhos elencam os acidentes com cortes, perfurações, queimaduras, dermatites como consequências dessa atividade, além da alta incidência de intoxicações alimentares e doenças parasitárias (Hoefel et al., 2013).

No Município de São José de Piranhas existem atualmente 12 catadores que realizam o seu trabalho frequentemente no próprio lixão (Figura 7), e alegam que ali está quase todo o seu sustento, sendo que a renda mensal é completada com o programa de auxílio do governo, o Bolsa Família, ainda segundo as informações deles, existem cerca de 4 catadores que trabalham nas ruas da cidade catando o lixo que ainda não foi levado para o vazadouro (Figura 8). Todos os catadores consultados afirmam que guardam os materiais coletados na própria residência, ou bem próximo dela. Portanto, é efetiva a existência de catadores, sejam eles nas ruas ou no lixão, sendo este indicador classificado como DESFAVORÁVEL à sustentabilidade, devido a atividade de catação ocorrer no município sem nenhum tipo de regulamentação, tendo em vista que os catadores não estão engajados em nenhum tipo de associação ou cooperativa.

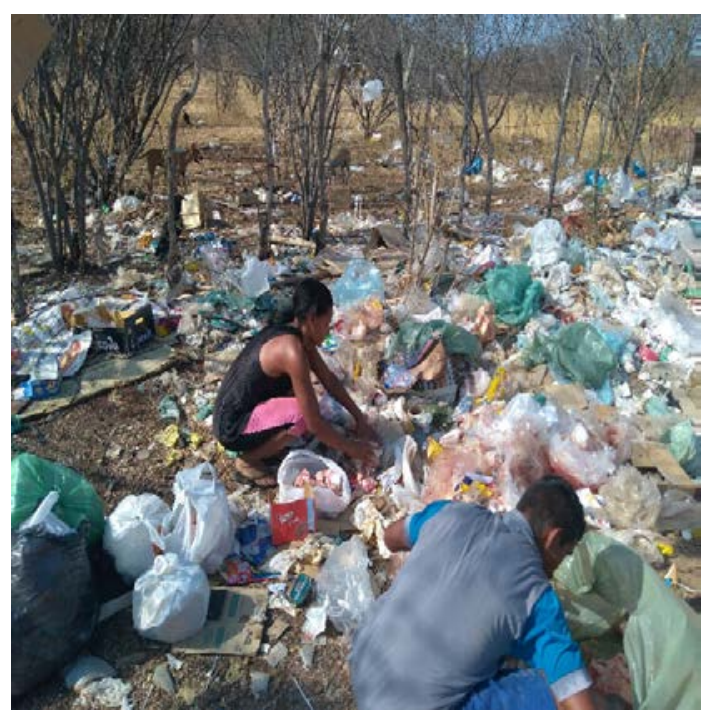

Figura 7. Catadores de resíduos sólidos no vazadouro do lixão do Município de São José de Piranhas, 2018. 


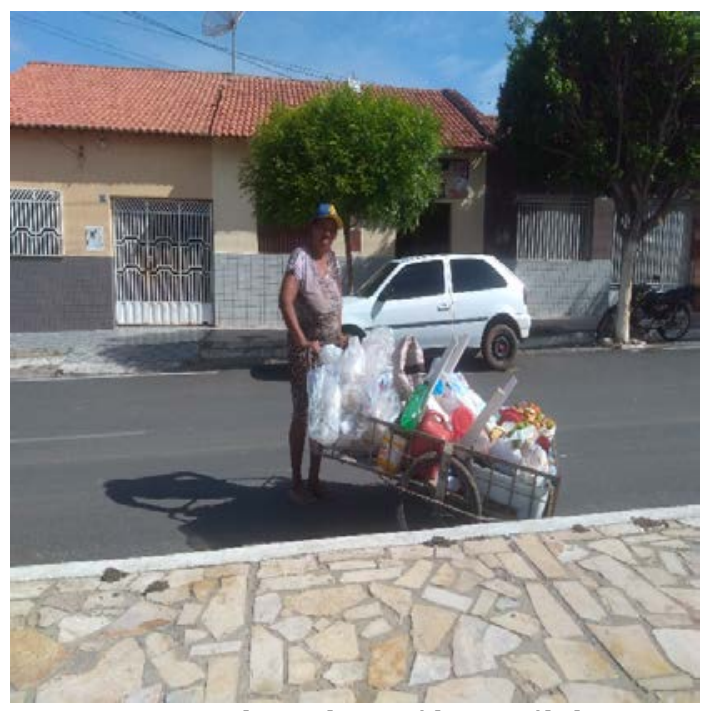

Figura 8. Catadora de resíduos sólidos nas ruas na Cidade de São José de Piranhas, 2018.

Destinação dos resíduos dos serviços de saúde. Segundo os servidores de um PSF e da policlínica do Município de São José de Piranhas, os resíduos provenientes dos órgãos da saúde do município são administrados por uma empresa, especialista nesse tipo de lixo. Em cada unidade de saúde há um recipiente especifico para se colocar o lixo que pode estar infectado (Figura 9), e uma vez por mês um veículo da empresa recolhe todos os recipientes no município.

De acordo com o manual de gerenciamento de resíduos de saúde da Angência Nacional de Saúde,

Os resíduos de serviços de saúde são parte importante do total de resíduos sólidos urbanos, não necessariamente pela quantidade gerada (cerca de $1 \%$ a $3 \%$ do total), mas pelo potencial de risco que representam à saúde e ao meio ambiente. Os RSS são classificados em função de suas características e consequentes riscos que podem acarretar ao meio ambiente e à saúde (Brasil, 2006).

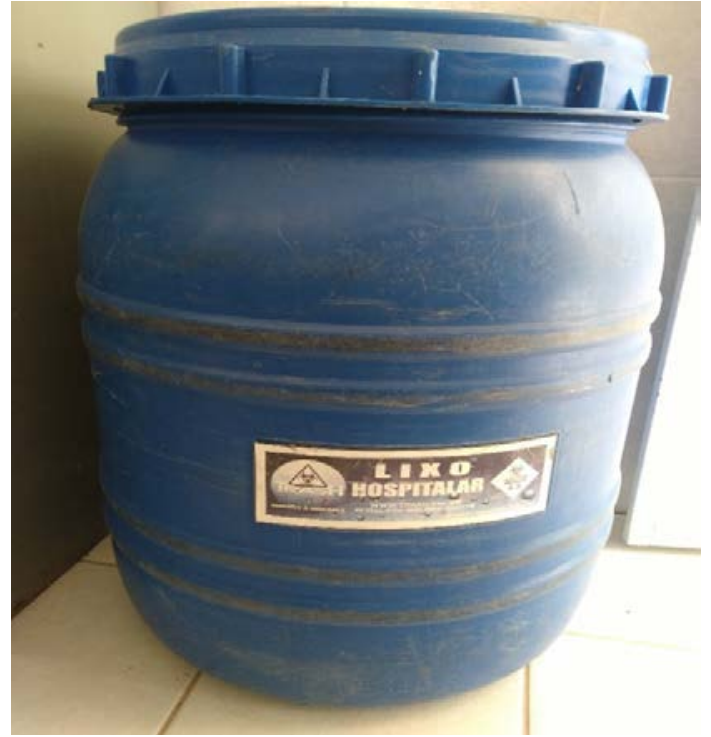

Figura 9. Recipiente específico para lixo contaminado, utilizado nas unidades de saúde do Município de São José de Piranhas, 2018.

No Município de São José de Piranhas, a prefeitura encarrega-se de pagar a empresa pelos seus serviços, sendo esta a responsável pela coleta, transporte e incineração dos resíduos de maneira legalizada e correta. Assim, é possível avaliar este indicador como FAVORÁVEL, pela não destinação dos resíduos de saúde ao vazadouro a céu aberto do município.

Isolamento da unidade de disposição. 0 isolamento de uma determinada área pode ser feito mediante a construção de muros de alvenaria, cercas de madeira ou ainda grades metálicas. Segundo Moreira (2016) esse tipo de suporte é uma importante ferramenta na contenção e proteção contra possíveis animais que venham adentrar no complexo, além de manter todo o resíduo com peso leve dentro, por exemplo, sacolas e plásticos na localidade. 
No Município de São José de Piranhas, a cerca é construída por estacas de madeira e arame farpado, e com acesso aberto, como mostra a Figura 10, sem nenhum tipo de fiscalização daquilo que entra ou sai do vazadouro. Mesmo com a existência dessa barreira física foi verificado a presença de vários animais na unidade. Desse modo, o acesso para esses animais é facilitado e estes trafegam livremente entre a unidade de disposição e a estrada vicinal que margeia o vazadouro.

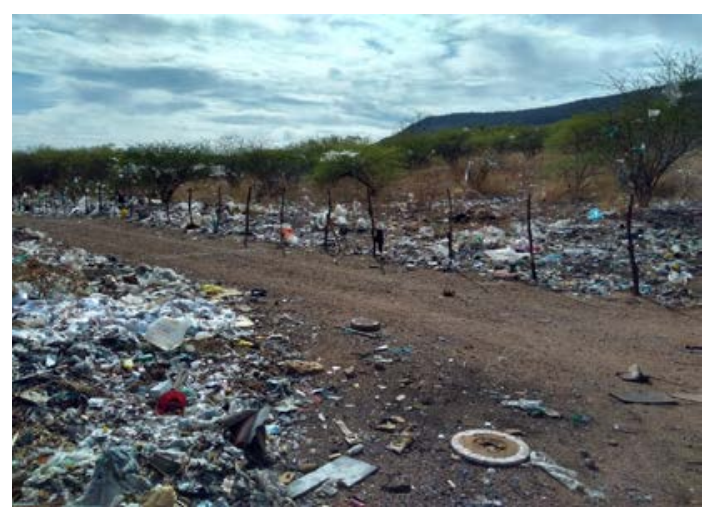

Figura 10. Cercas que delimitam todo o vazadouro do lixão do Município de São José de Piranhas, 2018.

Outro problema que decorre desse tipo de cercamento é que muitos materiais plásticos, principalmente sacolas são levadas pelo vento para terrenos vizinhos e até para algumas residências mais próximas. Nesse sentido, esse tipo de cercamento se torna ineficiente sendo considerado como DESFAVORÁVEL.

\section{Estado}

\section{Análise dos Indicadores de}

Qualidade do ar (drenagem dos gases). 0 sistema de drenagem de gases (biogás) tem a função de drenar o gás que se origina da decomposição biológica da matéria orgânica, evitando com isso sua migração através de meios porosos que constituem o subsolo, podendo se acumular em redes de esgoto, fossas, poços e sob edificações. Porém tal sistema está presente apenas em aterros sanitários (Brito Filho, 2005).

No Município de São José de Piranhas o lixo fica exposto a céu aberto em sua destinação final, não sendo uma prática que contribua para a preservação dos recursos naturais. Por isso, nesse tipo de destinação não se observa a presença de nenhum sistema que possa drenar os gases produzidos a partir do acumulo dos resíduos, o que permite avaliar este indicador como DESFAVORÁVEL à sustentabilidade do município.

$\begin{array}{cccc}\begin{array}{c}\text { Qualidade } \\ \text { (aproveitamento }\end{array} & \text { de } & \text { gases). } & \text { ar } \\ \text { trabalho realizado } & \text { no } & \text { município } & \text { de }\end{array}$ Nazarezinho, Estado da Paraíba, Soares et al. (2017) constataram que o aproveitamento dos gases permite inúmeros benefícios, como diminuição dos gases poluentes e, assim, uma menor agressão à natureza. 0 que torna 0 aproveitamento dos gases produzidos, uma fonte de lucro a partir de um gerenciamento de resíduos sólidos adequado, fazendo com que os impactos ao meio ambiente sejam menos frequentes.

Assim, de acordo com os dados levantados nesta pesquisa por intermédio de questionário aos 51 atores sociais e institucionais, e a partir das visitas realizadas ao local de disposição do lixo, verificou-se que não há presença de nenhum tipo de sistema de aproveitamento de gases, o que avalia este indicador como DESFAVORÁVEL.

\section{Existência de instalações administrativas. Segundo Moreira} (2016), é bastante comum encontrarmos nos aterros sanitários instalações administrativas, que tem como função coordenar o gerenciamento dos resíduos sólidos ali depositados.

O Município de São José de Piranhas não apresenta o aterro sanitário como opção para o destino final do lixo, e 
também não apresenta nenhum tipo de instalação administrativa no vazadouro, popularmente conhecido como lixão. 0 que classifica esse indicador como DESFAVORÁVEL a sustentabilidade.

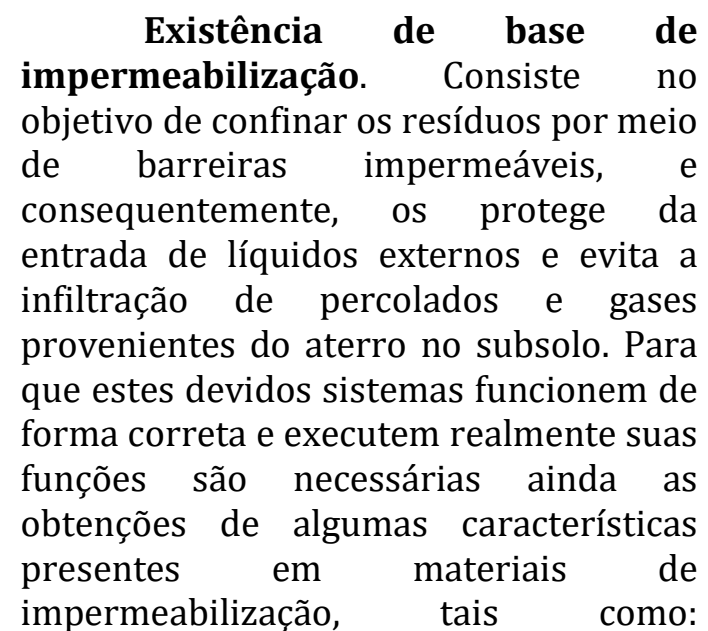
estanqueidade; durabilidade; resistência mecânica; resistência a intempéries e compatibilidade físico-químico-biológica com os resíduos a serem aterrados (Locastro e Angelis, 2016).

A base de impermeabilização é essencial para os aterros, entretanto no Município de São José de Piranhas a disposição é feita em vazadouro a céu aberto, logo, não há qualquer sistema de impermeabilização. Desse modo, essa variável fica avaliada como DESFAVORÁVEL do ponto de vista da sustentabilidade.

\footnotetext{
Frequência de cobertura dos resíduos sólidos. É comum observarmos a cobertura de resíduos sólidos em aterros sanitários, tal processo tem como objetivo formar uma barreira física visando impedir a entrada de água da chuva no interior do aterro, o que poderia comprometer a sua estabilidade física e provocar assim um acréscimo na geração do percolado. Além disso, é necessário precaver-se contra as falhas na superfície, promover a resistência à erosão dos taludes, a qual compromete a estabilidade do sistema de cobertura, controlar a combustão espontânea, diminuir a exalação de odores, evitar a disseminação de vetores
}

e pássaros e preservar a saúde humana e o meio ambiente (Silva, 2008).

No Município de São José de Piranhas no presente estudo, não existe aterro sanitário, e consequentemente não há o processo de cobertura dos resíduos sólidos, haja visto que o local de destinação final dos resíduos sólidos trata-se de um vazadouro a céu aberto, portanto este indicador é avaliado como DESFAVORÁVEL à sustentabilidade do município supramencionado.

Drenagem do chorume. De acordo com Serafim et al. (2003),

Chorume é um líquido escuro gerado pela degradação dos resíduos em aterros sanitários. Ele é originário de três diferentes fontes: Da umidade natural do lixo, aumentando no período chuvoso; Da água de constituição da matéria orgânica, que escorre durante o processo de decomposição; Das bactérias existentes no lixo, que expelem enzimas, enzimas essas que dissolvem a matéria orgânica com formação de líquido; 0 impacto produzido pelo chorume sobre o meio ambiente está diretamente relacionado com sua fase de decomposição (Serafim et al., 2003).

As técnicas que em geral são utilizadas para tratamento de rejeitos industrial têm sido empregadas para tratamento de chorume, incluindo os tradicionais processos biológicos, aeróbico e anaeróbico, como também uma variedade de processos de físicos e químicos (Silva et al., 2012a). Assim, este indicador é classificado como DESFAVORÁVEL à sustentabilidade do município, haja visto que o mesmo não realiza nenhum processo de drenagem de chorume.

Tratamento de chorume na mesma área da unidade. Diante da magnitude do problema e em virtude de sua complexidade, o tratamento do chorume é um desafio do saneamento 
ambiental, considerando-se as viabilidades técnica e econômica. 0 tratamento do chorume permite o lançamento do efluente tratado com qualidade suficiente para não causar danos ambientais e compatibilizar a técnica de aterramento dos resíduos sólidos urbanos com a legislação ambiental (Giordano et al., 2011).

Porém, de acordo do com as informações dos atores sociais entrevistados e em conformidade com 0 que foi observado durante as visitas ao vazadouro, o Município de São José de Piranhas não realiza o processo de tratamento de chorume, o que permite avaliar este indicador como DESFAVORÁVEL.

Licenciamento ambiental. 0 licenciamento é também um dos instrumentos da Política Nacional do Meio Ambiente (PNMA), cujo objetivo é agir preventivamente sobre a proteção do bem comum do povo - o meio ambiente - e compatibilizar sua preservação com o desenvolvimento econômico-social. Ambos, essenciais para a sociedade, são direitos constitucionais. A meta é cuidar para que o exercício de um direito não comprometa outro igualmente importante (Brasil, 2007).

De acordo com as informações prestadas pelos atores institucionais de São José de Piranhas, o terreno utilizado como local de disposição do lixo urbano é de propriedade privada, e não possui licenciamento ou qualquer outro tipo de permissão para o funcionamento do mesmo. Logo, este indicador é classificado como DESFAVORÁVEL à sustentabilidade do município.

Monitoramento ambiental. Em consonância com o que diz o Programa Nacional do Meio Ambiente II (PNMA, 2009) entende-se por monitoramento ambiental o conhecimento e acompanhamento sistemático da situação dos recursos ambientais dos meios físicos e biológicos, buscando a recuperação, melhoria ou manutenção da qualidade ambiental. A qualidade ambiental está relacionada ao controle de variáveis ambientais, que se alteram, seja em função das ações antrópicas, seja em função de transformações naturais.

Desta forma, no município onde foi realizado este estudo, não foi observado nenhum tipo de monitoramento ambiental, por se tratar de um vazadouro a céu aberto em que não há preocupação por parte do poder público com a disposição final dos resíduos produzidos, o que avalia este indicador como DESFAVORÁVEL do ponto de vista da sustentabilidade.

Impacto

Análise dos Indicadores de Doenças envolvendo a população no entorno do lixão. De acordo com Soares (2017) os famosos lixões (vazadouros a céu aberto) são locais propícios a proliferação de doenças, haja visto que eles fornecem condições necessárias para 0 desenvolvimento de bactérias, fungos e vírus. Moreira (2016) em trabalho realizado em Aurora - CE, afirma que o contágio por esses vetores é mais provável para as pessoas que estão em contato com a unidade de disposição, residindo próximo ou dentro da mesma.

No decorrer desta pesquisa foi identificado que não há grande proximidade do vazadouro em relação à população, pois o mesmo localiza-se a uma distância de aproximadamente $4 \mathrm{~km}$ das residências do município. De acordo com a secretaria de saúde e com enfermeiras de alguns PSFs (Postos de Saúde) do município de São José de Piranhas, não se observa doenças envolvendo a população que reside no entorno do vazadouro, que estejam relacionadas com o lixo. Porém grande parte dos entrevistados alegou, sentir incômodo com a fumaça, proveniente da queima dos resíduos, mas não foi constatado nenhum tipo de doença relacionada a ela. Assim, este indicador é classificado como FAVORÁVEL para a sustentabilidade do município, pois não 
são observadas doenças relacionadas ao lixão.

Poluição dos corpos hídricos. Os recursos hídricos são compostos por lençóis freáticos, rios e açudes que ficam próximos ou em contato com os locais de disposição final. A contaminação desses mananciais depende inteiramente do tipo de localidade que foi construída e como essa é mantida. Aterros sanitários dispõem de camadas de impermeabilização que impedem a contaminação desses mananciais pelo chorume. Em lixões que não possuem um sistema de impermeabilização eficiente e com ajuda da chuva a contaminação pode ser facilitada (Moreira, 2016).

Não se sabe ainda se há algum lençol freático a baixo do vazadouro a céu aberto utilizado como destino final dos resíduos sólidos produzidos em São José de Piranhas - PB. E não há contato direto com nenhum curso de rio, riacho ou açude, pois o mesmo está localizado a uma distância grande do reservatório de água mais próximo, que faz o abastecimento de toda a cidade. Portanto, este indicador é classificado como FAVORÁVEL à sustentabilidade do município.

Má utilização do espaço. Em conformidade com o trabalho de Soares (2017) no Município de Nazarezinho, Estado da Paraíba, é considerado como sendo desfavorável à sustentabilidade a presença de um vazadouro a céu aberto no município, tendo em vista que o mesmo prejudica a paisagem na qual se insere, bem como o solo, os animais e as pessoas.

No Município de São José de Piranhas o vazadouro está inserido em uma área de mata nativa e formando um elo de degradação ambiental por manter contato direto com a natureza e contaminando o solo, além de produzir vetores de doenças. Nos últimos anos o vazadouro tem aumentado o seu tamanho, devido ao aumento na produção dos resíduos. Portanto, este indicador é avaliado como DESFAVORÁVEL à sustentabilidade, considerando que o espaço de destinação final poderia ser utilizado de maneira mais coerente com a natureza, preservando os fatores bióticos e abióticos do local.

Poluição visual. Para Goulart Junior et al. (2013), a poluição visual ocasionada na degradação do ambiente é fruto da violação estética de um padrão paisagístico médio a ser aferido em cada caso, seja afetando uma paisagem naturalmente bela ou portadora de outro ponto relevante, ou alterando uma paisagem urbana de maneira desarmônica e agressiva. A poluição visual gera desarmonia ou desequilíbrio no meio ambiente artificial, prejudicando o bem estar da população, comprometendo a saúde das pessoas, através de efeitos psicológicos difíceis de serem diagnosticados.

No Município de São José de Piranhas esta poluição é mais frequente nas proximidades do lixão, principalmente às margens da rodovia PB-400, que liga São José de Piranhas a Monte Horebe, onde os resíduos leves (menos densos), como papel e sacos plásticos, são levados por ação do vento para perto das casas e propriedades vizinhas, ou quando são derrubadas no transporte até o vazadouro. Dessa forma, esse indicador é avaliado como DESFAVORÁVEL à sustentabilidade do município supramencionado.

Contaminação de animais domésticos. Existem muitos município no Brasil, que não dispõem de aterro sanitário para fazer o deposito dos resíduos sólidos produzidos pela população. Assim, a presença de "lixões" é frequente na maioria dos município, sendo que os mesmos em geral não possuem cercamentos que impeçam a entrada de animais. Nesta pesquisa, se constatou que o lixão possui cercas de arame farpado, porém com espaços que 
permitem o livre acesso de vários animais domésticos.

Estes animais passam a consumir os resíduos e assim ficam em condição de risco, podendo adquirir doenças, que podem inclusive chegar a atingir a população que mantém contato direto ou indireto com esses animais. Assim, a presença de animais no vazadouro, contribui para o aumento na exposição às doenças ou qualquer tipo de dano a saúde de uma população. Diante disso, este indicador é classificado como DESFAVORÁVEL à sustentabilidade.

Alagamento de vias públicas. Em seu trabalho realizado no Município de Aurora, Estado do Ceará, Moreira (2016) afirma que o alagamento das vias públicas é causado pela disposição indevida de resíduos em locais não apropriados a exemplo de calçadas e terrenos baldios, dessa forma, em períodos chuvosos esse material é transportado até os bueiros e esgotos, impedindo assim o escoamento da água proveniente das chuvas, o que resulta em alagamentos e dispersão de lixo pelas vias públicas.

De acordo com todos os 51 atores sociais entrevistados, não existe no Município de São José de Piranhas alagamento de vias públicas, nem mesmo em períodos chuvosos é possível observar tal fenômeno. Portanto, esse indicador é avaliado como FAVORÁVEL à sustentabilidade, por não ocorrer alagamento das vias públicas.

\section{Resposta}

Análise dos Indicadores de

Existência de associação ou cooperativa. De acordo com Luttner et al. (2015), o surgimento das associações ou cooperativas se deu devido a dois fortes fatores, ao reconhecimento da importância do meio ambiente na década de 1980, e a reestruturação econômica, com a globalização da produção e dos mercados produzindo milhares de desempregados e a tendência à defasagem das relações de emprego e trabalho. Neste sentido, essas organizações se pautaram dentro dos princípios da economia solidária e foram configurando-se como uma alternativa de emprego, renda e inclusão profissional para um expressivo contingente de trabalhadores das cidades que se encontravam à margem do mercado formal de trabalho.

A presença de uma associação ou cooperativa de resíduos recicláveis nos municípios contribui para o desenvolvimento econômico e sustentável das cidades, contudo, se faz necessário empenho da população, ajudando na separação dos materiais e no descarte correto do lixo produzido. A separação e reciclagem dos materiais desprezados pela sociedade, além de fornecer renda para os que realizam essa atividade, contribui para o aproveitamento dos materiais, prolongando sua vida útil e diminuindo os impactos ambientais (Soares, 2017).

Pela não existência de associações ou cooperativas no Município de São José de Piranhas, este indicador é classificado como DESFAVORÁVEL à sustentabilidade municipal.

\section{Tratamento de resíduos} sólidos urbanos. De acordo com Moreira (2016) existe mais de uma maneira de tratar os resíduos no intuído de reduzir seu volume, patogenicidade e poder de agressão à natureza. Três métodos são mais comuns, o mecânico, o bioquímico e o térmico. Cada um sendo aplicado em conformidade com as particularidades de cada município. Os catadores executam papel relevante na redução do volume desses resíduos e dos impactos ambientais.

No Município de São José de Piranhas não existe aterro sanitário, processo adequado de incineração de resíduos, coleta seletiva, reciclagem dos materiais descartados ou compostagem do material orgânico. 0 indicador em questão é avaliado como DESFAVORÁVEL por não possuir 
nenhuma forma de tratamento de seus resíduos, o que não beneficia a sustentabilidade do município.

Existência de política pública. As decisões e análises a respeito da política pública implicam na resolução de questões, como quem ganha o quê, por quê e que diferença faz. Assim é necessária a participação da coletividade na realização da proteção e do desenvolvimento da qualidade ambiental, acentuada pelos atos de planejamento e da gestão ambiental que elevam a finalidade do sistema participativo, do conhecimento e da mobilização da coletividade (Rodrigues e Menti, 2016).

Soares (2017) coloca em seu trabalho que o resultado da aplicação de políticas públicas que visem os resíduos sólidos nos municípios é o incentivo a separação do lixo doméstico, as campanhas de redução de consumo desenfreado e descarte adequado, como a implantação de leis e regras que procurem não agredir a natureza e consequentemente a preservação dos recursos naturais. Logo, no tocante a existência de políticas públicas de tratamento dos resíduos sólidos em São José de Piranhas, este indicador é avaliado como DESFAVORÁVEL à sustentabilidade do município por não se observar nenhuma atividade relacionada às políticas públicas.

\section{Atividade de educação} ambiental. Soares et al. (2007) afirmam que a educação ambiental é o principal instrumento de transformação, sendo essencial para o desenvolvimento de uma consciência crítica em relação ao meio ambiente, gerando comprometimento e responsabilidade da população nas ações de saneamento e saúde. Ela tem sido bastante utilizada como instrumento para resolver os problemas associados aos resíduos sólidos, desde a geração, coleta, transporte até a disposição no destino final.
A educação ambiental certamente contribui de maneira positiva para o bom engajamento da gestão ambiental em qualquer localidade, tendo em vista que é necessário que a população compreenda a importância de se cuidar bem dos resíduo sólidos, e é a educação ambiental quem promove tal entendimento. De acordo com os atores sociais entrevistados, a maioria respondeu que não existe atividades de educação ambiental na cidade. Em declaração a esse questionamento, alguns professores afirmaram tratar o assunto em algumas aulas, mas que não há nada no sentido de tentar de fato desenvolver o tema de maneira complexa e integrada. Do ponto de vista da sustentabilidade, esse indicador é avaliado como DESFAVORÁVEL pela não existência de atividades de educação ambiental no município.

\section{Providências de melhoramento} com relação ao destino final dos resíduos. Algumas providências podem ser tomada, com o intuito de mitigar ou excluir totalmente os danos causados pela má gestão dos resíduos sólidos, tais como medidas de tratamento por meio de redução mecânica, química ou incineração, ou ainda a construção de locais adequados com os parâmetros da sustentabilidade, por exemplo, aterros sanitários com uma taxa de perturbação ambiental reduzida (Moreira, 2016).

Partindo para o nível de unidade de disposição, ações como a formação de cooperativas pelos catadores também reduzem significativamente os efeitos da degradação desses resíduos no ambiente, além disso, uma população engajada em projetos e que visem estabelecer um vínculo de participação ativa entre população e tomadores de decisão contribui decisivamente para $o$ melhoramento do ambiente que se vive (Moreira, 2016).

Mesmo diante de tantas possibilidades de melhoria da qualidade de vida da população, em São José de Piranhas nenhuma é posta em debate, 
nem pelos representantes do poder público, nem pela população em geral. Dessa forma, este indicador é avaliado como DESFAVORÁVEL a sustentabilidade, porque não existem providências voltadas ao melhoramento dos problemas da gestão ambiental de resíduos sólidos.

\section{Política Nacional dos Resíduos} Sólidos. Soares (2017) afirma que em 2 de agosto de 2010, foi aprovada a Lei $\mathrm{n}^{\mathrm{o}}$ 12.305/2010, referente à Política Nacional dos Resíduos Sólidos (Brasil, 2010), que estabelece o interesse social, econômico e sustentável do país, estados e municípios no gerenciamento dos resíduos sólidos e semissólidos produzidos nos meios urbanos e rurais da nação. Orienta os gestores de todo o país a colocar em prática a coleta seletiva nos municípios, bem como a reciclagem dos materiais provenientes dela, com preferência aos catadores de cooperativas ou associações locais, e responsabiliza fabricantes, distribuidores, importadores e comerciantes pelo recolhimento e destinação ambientalmente correta dos resíduos.

A lei supramencionada ainda aponta a importância da política dos 4R's (Reduzir-Reutilizar-Restaurar-Reciclar), que combate o consumo desenfreado, além de incentivar a compostagem e o processo de aproveitamento energético dos resíduos com destinação final adequada. Entre os benefícios trazidos pelo cumprimento da lei, é possível ressaltar o aumento da qualidade de vida da população, a restauração das matas nativas e a diminuição das espécies ameaçadas com o descarte ilegal de produtos na Natureza (Soares, 2017).

Desta forma, considerando os vários pré-requisitos estabelecidos pela Lei $\mathrm{n}$ - 12.305, de 2 de agosto de 2010 (Brasil, 2010), para o melhoramento da gestão ambiental, e considerando que o município de São José de Piranhas descumpre essa lei em vários aspectos, este indicador é classificado como DESFAVORÁVEL a sustentabilidade.

Galpão para separação dos resíduos sólidos. É possível eliminar o custo de equipamentos pesados na coleta porta a porta e obter um baixo custo sem perda da eficácia, através da separação realizada em galpão. É com a combinação adequada do transporte feito pelos catadores e por caminhões que se obtém o menor custo de transporte por tonelada, uma vez que o custo de um caminhão em operação é relativamente alto, somente se justificando quando a massa dos resíduos transportados for suficientemente concentrada (Brasil, 2008).

No Município de São José de Piranhas não existe galpão para separação dos resíduos sólidos, com isso, todos os resíduos coletados no município ficam depositados em um vazadouro a céu aberto, com a ressalva dos resíduos de saúde que são coletados por uma empresa especializada nesse trabalho. Por tanto este indicador é avaliado como DESFAVORÁVEL à sustentabilidade municipal, haja visto que os 12 catadores que trabalham no lixão realizam o processo de separação dos resíduos a céu aberto, devido à não existência de galpão.

\section{Coleta seletiva no município.}

Dentre as tecnologias mais eficazes para reduzir os impactos ambientais causados pela geração de resíduos sólidos urbanos, destaca- se a coleta seletiva de resíduos sólidos recicláveis, como o plástico, o metal, o vidro e o papelão, sendo uma alternativa ambientalmente correta e sustentável. Na coleta seletiva observamse vertentes socioeconômicas e socioambientais, sendo a coleta executada da maneira correta é possível que haja geração de empregos e renda para os catadores ligados a associações, ou mesmo os que trabalham individualmente. Enfatiza-se ainda que em alguns casos essa seja a renda única de sobrevivência e em outras situações 
são apenas complementares (Medeiros, 2015).

No Município de São José de Piranhas o sistema de coleta seletiva jamais foi implantado pela prefeitura, sendo que a população acumula em um único recipiente todos os resíduos produzidos, e esses ficam armazenados em um vazadouro a céu aberto. Dessa forma, este indicador é avaliado como DESFAVORÁVEL à sustentabilidade do município.

Um resumo dos resultados do modelo de indicadores de sustentabilidade PEIR para o lixão do Município de São José de Piranhas está apresentado na Tabela 2.

Tabela 2. Resultado geral do sistema de indicadores (PEIR).

\begin{tabular}{|c|c|c|}
\hline CATEGORIA & INDICADORES & SITUAÇÃO \\
\hline \multirow{8}{*}{ Pressão } & Coleta de lixo diretamente para o lixão & DESFAVORÁVEL \\
\hline & Coleta de lixo nos Bairros & FAVORÁVEL \\
\hline & Queima de resíduos a céu aberto & DESFAVORÁVEL \\
\hline & Presença de animais na área de disposição do lixão & DESFAVORÁVEL \\
\hline & Moradias na unidade de disposição & FAVORÁVEL \\
\hline & Existência de catadores & DESFAVORÁVEL \\
\hline & Destinação dos resíduos dos serviços de saúde & FAVORÁVEL \\
\hline & $\begin{array}{l}\text { Existência de algum tipo isolamento no local de } \\
\text { disposição dos resíduos sólidos }\end{array}$ & DESFAVORÁVEL \\
\hline \multirow{7}{*}{ Estado } & Qualidade do ar (drenagem de gases) & DESFAVORÁVEL \\
\hline & Qualidade do ar (aproveitamento dos gases) & DESFAVORÁVEL \\
\hline & Existência de instalações administrativas & DESFAVORÁVEL \\
\hline & Existência de base impermeabilizada & DESFAVORÁVEL \\
\hline & Frequência da cobertura dos resíduos sólidos & DESFAVORÁVEL \\
\hline & Drenagem do chorume & DESFAVORÁVEL \\
\hline & Tratamento de chorume na área da unidade & DESFAVORÁVEL \\
\hline & Licenciamento ambiental & DESFAVORÁVEL \\
\hline & Monitoramento ambiental & DESFAVORÁVEL \\
\hline \multirow{6}{*}{ Impacto } & Doenças envolvendo as populações no entorno do lixão & FAVORÁVEL \\
\hline & Poluição dos recursos hídrico & FAVORÁVEL \\
\hline & $\begin{array}{l}\text { Má utilização do espaço destinado à disposição final } \\
\text { dos resíduos }\end{array}$ & DESFAVORÁVEL \\
\hline & Poluição visual & DESFAVORÁVEL \\
\hline & Contaminação de animais domésticos & DESFAVORÁVEL \\
\hline & Alagamento das vias públicas & FAVORÁVEL \\
\hline \multirow{8}{*}{ Resposta } & Existência de associação ou cooperativa & DESFAVORÁVEL \\
\hline & Tratamento de resíduos sólidos urbanos & DESFAVORÁVEL \\
\hline & Existência de política pública & DESFAVORÁVEL \\
\hline & Atividade de educação ambiental & DESFAVORÁVEL \\
\hline & $\begin{array}{llll}\text { Providencia de melhoramento com relação à } \\
\text { Destinação final dos resíduos sólidos }\end{array}$ & DESFAVORÁVEL \\
\hline & Política nacional dos resíduos sólidos & DESFAVORÁVEL \\
\hline & Galpão para separação dos resíduos sólidos & DESFAVORÁVEL \\
\hline & Coleta seletiva no município & DESFAVORÁVEL \\
\hline
\end{tabular}

\section{Considerações finais}

Tomando por base o tema aqui discutido, fica evidente a recorrência com que o mesmo se apresenta nos debates acadêmicos e como ele influencia no desenvolvimento econômico. Trata-se portanto de um tema atual e de 
relevância para o bem estar da fauna e flora de qualquer lugar, bem como de todo o meio ambiente. Dessa forma, dar um destino adequado aos resíduos sólidos que nós produzimos é essencial para aumentar a qualidade de vida das pessoas e zelar pelo meio ambiente no qual estamos inseridos.

0 presente estudo utilizando $\mathrm{o}$ modelo de indicadores de sustentabilidade PEIR, contou com a aplicação de trinta e um indicadores de sustentabilidade no Município de São José de Piranhas. Dentre estes, apenas seis foram classificados como FAVORÁVEIS e vinte e cinco foram classificados como DESFAVORÁVEIS à sustentabilidade ambiental do município.

Muitos problemas graves puderam ser constatados, sendo que entre eles pode-se destacar a presença de um vazadouro a céu aberto, para onde todo o lixo urbano produzido é levado, fato este que infringe a lei da Política Nacional dos Resíduos Sólidos, o que torna o indicador coleta de lixo diretamente para o lixão DESFAVORÁVEL à sustentabilidade. Outro indicador desfavorável que merece destaque é a existência de catadores, sem a existência de associação ou cooperativa que possa regulamentar o trabalho dos mesmos, tonando o trabalho de alta periculosidade.

Dentre os indicadores que foram avaliados como FAVORÁVEIS pode-se destacar a destinação dos serviços de saúde, que é realizada de forma adequada, por uma empresa contratada pela prefeitura. Outro fato que merece atenção é a não presença de pessoas residindo dentro do vazadouro, o que configura 0 indicador Moradias na Unidade de Disposição como FAVORÁVEL à sustentabilidade.

Desta forma, fica evidente a necessidade de mudanças imediatas no gerenciamento dos resíduos sólidos urbanos em São José de Piranhas - PB. É necessário a implementação de projetos que visem ampliar a educação ambiental no município, a instalação de um aterro sanitário, seguindo todas as medidas preconizadas pela legislação vigente, o surgimento de cooperativas ou associações de catadores que regulamente o trabalho dos mesmos.

Assim, somente com a aliança entre os atores sociais e os atores institucionais, pautados no intuito de compreender e buscar atitudes novas para solucionar a problemática é que se torna possível reverter esse quadro de baixíssima qualidade para a sustentabilidade socioambiental no município supramencionado.

\section{Conflito de interesses}

Os autores declaram não haver conflito de interesses.

\section{Referências}

ABRELPE - Associação Brasileira das Empresas de Limpeza Pública e Resíduos Especiais. Panorama dos Resíduos Sólidos no Brasil. Rio de Janeiro: ABRELPE, 2015. Disponível em: <http://www.abrelpe.org.br/ Panorama/panorama2014.pdf>. Acesso em: 8 maio 2018.

Brasil. Ministério da Saúde. Agência Nacional de Vigilância Sanitária. Gerenciamento de resíduos de serviços de saúde. Brasília: ANVISA, 2006.

Brasil. Ministério das Cidades. Ministério do Meio Ambiente. Elementos para a organização da coleta seletiva e projeto dos galpões de triagem. Brasília: MMA; São Carlos: IAGRS-UFSCar, 2008.

Brasil. Tribunal de Contas da União. Cartilha de licenciamento ambiental. 2. ed. Brasília: TCU, 2007.

Brasil. Resolução CONAMA no 001, de 23 de janeiro de 1986. Disponível em: <http://www2.mma.gov.br/port/conama/re s/res86/res0186.html>. Acesso em: 8 maio 2018.

Brasil. Resolução CNS no 510, de 7 de abril de 2016. Disponível em: <http://conselho.saude.gov.br/resolucoes/2 016/Reso510.pdf>. Acesso em: 8 maio 2018.

Brasil. Lei no 12.305, de 2 de agosto de 2010. Institui a Política Nacional de Resíduos 
Sólidos; altera a Lei $\mathrm{n}^{-}$9.605, de 12 de fevereiro de 1998; e dá outras providências. Disponível em: <http://www.planalto.gov. br/ccivil_03/_ato2007-2010/2010/lei/ 112305.htm>. Acesso em: 8 maio 2018.

CPRM - Serviço Geológico do Brasil. Projeto cadastro de fontes de abastecimento por água subterrânea Estado da Paraíba: diagnóstico do Município de São José de Piranhas. Recife: CPRM/PRODEEM, 2005.

Cunha, V.; Caixeta Filho, J.V.C. Gerenciamento da coleta de resíduos sólidos urbanos: estruturação e aplicação de modelo não-linear de programação por metas. Gestão e Produção, v. 9, n. 2, p. 143-161, 2002. https://doi.org/10.1590/S0104-530X 2002000200004

Brito Filho, L. F. Estudo de gases em aterros de resíduos sólidos urbanos. Rio de Janeiro: Universidade Federal do Rio de Janeiro, 2005. (Dissertação de mestrado).

Giordano, G.; Barbosa Filho, O.; Carvalho, R. J. Processos físico-químicos para tratamento do chorume de aterros de resíduos sólidos urbanos. Coletânea em Saneamento Ambiental, Série Temática Tecnologias Ambientais, v. 4, p. 1-179, 2011. Disponível em: $\quad<$ http://www.coamb.eng.uerj.br/ download/coamb-TA-Volume4.pdf>. Acesso em: 8 maio 2018.

Hoefel, M. G.; Carneiro, F. F.; Santos, L. M. P.; Gubert, M. B.; Amate, E. M.; Santos, W. Acidentes de trabalho e condições de vida de catadores de resíduos sólidos recicláveis no lixão do Distrito Federal. Revista Brasileira de Epidemiologia, v. 16, n. 3, p. 764-785, 2013. https://doi.org/10.1590/S1415-790X 2013000300020

IBGE - Instituto Brasileiro de Geografia e Estatística. 2010. Disponível em: <https://cidades.ibge.gov.br/brasil/pb/saojose-de-piranhas/panorama>. Acesso em: 7 maio 2018 .

Goulart Junior, R.; Pagliarini Junior, S. N.; Mallysz, S. T. Meio ambiente: poluição visual no meio urbano. Anais do VIII Encontro de Produção Científica e Tecnológica, Campo Mourão-PR, 2013. Disponível em: <http://www.fecilcam.br/nupem/anais_viii_ epct/PDF/TRABALHOS-COMPLETO/AnaisCET/GEOGRAFIA/rjuniortrabalhocompleto.p df>. Acesso em: 29 out. 2018.
Locastro, J. K.; Angelis, B. L. D. Barreiras de impermeabilização: configurações aplicadas em aterros sanitários. Revista Eletrônica em Gestão, Educação e Tecnologia Ambiental, v. 20, n. 1, p. 200-210, 2016.

Luttner, C. M. A.; Silva, L. R.; Ferreira, L. C. D. As experiências das diferentes formas de remuneração em associações e cooperativas de catadores de materiais recicláveis dos municípios da Região Metropolitana de Belo Horizonte: entre desafios e possibilidades na economia solidária. In: Pereira, B. C. J.; Goes, F. L. Catadores de materiais recicláveis: um encontro nacional. São Paulo: IPEA, 2015. p.362-374. Disponível em: <http://www.ipea.gov.br/portal/images/sto ries/PDFs/livros/livros/160331_livro_catad ores_cap_17.pdf>. Acesso em: 29 out. 2018.

Medeiros, M. S. Coleta seletiva de resíduos sólidos urbanos: acompanhamento do projeto Lixo Social na Cidade de São José do Seridó-RN. Caicó: Universidade Federal do Rio Grande do Norte, 2015. (Monografia de Bacharelado em Geografia).

Moreira, R. S. Contribuições do sistema de indicador de sustentabilidade PressãoEstado-Impacto-Resposta (P-E-I-R) na análise situacional do gerenciamento dos resíduos sólidos urbanos em Aurora-CE. Cajazeiras: Universidade Federal de Campina Grande, 2016. (Trabalho de Conclusão de Curso de Graduação em Ciências Biológicas).

Moreira, R. S.; Barros, J. D. S.; Silva, J. L. A.; Araújo, J. T.; Pordeus, A. V. Sustentabilidade socioambiental no gerenciamento de resíduos sólidos urbanos: estudo de caso com aplicação do modelo Pressão-EstadoImpacto-Resposta. Revista Espacios, v. 38, n. 58, p. 1-5, 2017. Disponível em: <https://www.revistaespacios.com/a17v38n 58/a17v38n58p05.pdf>. Acesso em: 21 mar. 2019.

Morgado, T. C.; Ferreira, O. M. Incineração de resíduos sólidos urbanos, aproveitamento na co-geração de energia: estudo para a Região Metropolitana de Goiânia. Goiânia: Pontifícia Universidade Católica de Goiás, 2006. Disponível em: <http://web-resol.org/textos/incineracao _de_residuos_solidos_urbanos,.pdf $>$. Acesso em: 26 out. 2018.

Oliveira, C. Impactos ambientais derivados de atividades industriais: o caso do Cilo IV. 
Londrina: Universidade Estadual de Londrina, 2006. (Monografia de Geociências).

PNMA - Programa Nacional do Meio Ambiente. PNMA II - Fase II: Componente Desenvolvimento Institucional. Brasília: PNMA, 2009.

Prodonov, C. C.; Freitas, E. C. Metodologia do trabalho científico: métodos e técnicas da pesquisa e do trabalho acadêmico. 2. ed. Novo Hamburgo: Feevale, 2013.

Rodrigues, C. R. P.; Menti, M. M. Resíduos sólidos: gerenciamento e políticas públicas federais. Caderno do Programa de PósGraduação de Direito da UFRGS, v. 11, n. 3, p. 59-79, 2016. https://doi.org/10.22456/ 2317-8558.66487

Serafim, A. C.; Gussakov, K. C.; Silva, F.; Coneglian, C. M. R.; Brito, N. N.; Dragoni Sobrinho, G.; Tonso, S.; Pelegrini, R. Chorume, impactos ambientais e possibilidades de tratamentos. Anais do III Fórum de Estudos Contábeis, Rio Claro: CESET-UNICAMP, 2003. Disponível em: <https://www.tratamentode agua.com.br/wp-content/uploads/2016/ 06/Chorume-impactos-ambientais-epossibilidades-de-tratamento.pdf $>$. Acesso em: 26 out. 2018.

Silva, A. T. A. Aspectos meteorológicos e balanço hídrico em um aterro de resíduos sólidos urbanos. Rio de Janeiro: Universidade Federal do Rio de Janeiro, 2008. (Dissertação de Mestrado em Engenhara Civil).

Silva, E. L.; Menezes, E. M. A pesquisa e suas classificações. In: Silva, E. L.; Menezes, E. M. Metodologia da pesquisa e elaboração de dissertação. Florianópolis: UFSC, 2005. p. 19-23.

Silva, S. S. F.; Cândido, G. A.; Ramalho, A. M. C. Diagnóstico situacional dos resíduos sólidos urbanos no Município de Cuité-PB: uma aplicação do sistema de indicador de sustentabilidade pressão - estado - impacto resposta (p-e-i-r). Revista Gestão Industrial, $\quad$ v. $8, \quad$ n. 3 , p. 72-90. 2012a. https://doi.org/10.3895/S1808-0448 2012000300003

Silva, S. S. F.; Santos, J. G.; Cândido, G. A.; Ramalho, A. M. C. Indicador de Sustentabilidade Pressão - Estado - Impacto Resposta no diagnóstico do cenário sócioambiental resultante dos resíduos sólidos urbanos em Cuité-PB. REUNIR - Revista de Administração, Contabilidade e Sustentabilidade, v. 2, n. 3, p. 76-93, 2012b. https://doi.org/10.18696/reunir.v2i2.68

Soares, A. M. Avaliação do gerenciamento de resíduos sólidos através do Sistema de Indicadores de Sustentabilidade PressãoEstado-Impacto-Resposta (PEIR) no Município de Nazarezinho-PB. Cajazeiras: Universidade Federal de Campina Grande, 2017. (Monografia de Licenciatura em Ciências Biológicas).

Soares, A. M.; Barros, J. D. S.; Bezerra, D. S. Aplicação do Sistema de Indicadores de Sustentabilidade Pressão-Estado-ImpactoResposta (PEIR) no Município de Nazarezinho-PB: enfoque no estado dos resíduos sólidos. Revista Brasileira de Gestão Ambiental e Sustentabilidade, v. 4, n. 8, p. 255-262, 2017. https://doi.org/ $10.21438 /$ rbgas. 040802

Soares, L. G. C.; Salgueiro, A. A.; Gazineu, M. H. P. Educação ambiental aplicada aos resíduos sólidos na Cidade de Olinda-PE: um estudo de caso. Revista Ciências e Tecnologia, v. 1, p. 1-9, 2007. Disponível em: <http://webresol.org/textos/artigo5.pdf>. Acesso em: 26 out. 2018.

Informação da Licença: Este é um artigo Open Access distribuído sob os termos da Licença Creative Commons Attribution, que permite uso irrestrito, distribuição e reprodução em qualquer meio, desde que a obra original seja devidamente citada. 